By ROBERT FINLEY DELANEY

\title{
The Administration of Intelligence Archives
}

Mr. Delaney is director of the Research Center of the Naval Intelligence School and instructor in intelligence research and analysis.

W ORLD War II and its aftermath have resulted in the vast and continuing expansion of strategic intelligence services within both the civil and the military components of our federal government. Since an understanding of the term "strategic intelligence" is fundamental to any discussion of the organization of intelligence archives, a definition should be given at the outset. In its simplest terms, strategic intelligence is that knowledge which our top civilian and military planners must have in order to safeguard our national security. A strategic intelligence service, therefore, is the organization responsible for providing that knowledge.

From this definition it is apparent that a conception of intelligence service in terms of secret codes and beautiful lady spies, however intriguing, is overly simplified. The technology and sociology of the present-day world are such that continuous accurate evaluations of advances, attitudes and policies of all nations-potential foes and friends alike-are vital to the formulation of our own foreign policies and our military preparedness for defense. Without an adequate and efficient intelligence organization geared to furnish these evaluations, the United States might well face political or military defeat-or both. Neither the codes nor the feminine spies, however accomplished, are equal to so great a task. Hence, although the need for secrecy and security is still paramount, the operation of a modern intelligence agency is no longer so romantic as it has been pictured in fiction and the motion picture. It is, in fact, organized and operated along the same or similar lines as any other governmental administrative agency. With what is fundamentally a research job to do, the intelligence service requires an effective organization of an expert staff to produce those orderly, factual and analytic reports needed by our policy makers in their efforts to choose those courses of action best calculated to insure the preservation of world peace and develop that kind of international harmony and accord essential to the preservation of our civilization and its ideals.

This paper is concerned with the research center of an intelligence organization, a key service section in an organization responsible for the activities outlined above. In some respects, the research center defies description for no matter how the duties of a center are defined, there are infinite ramifications to the use of the tools and materials housed therein. It may be said in general that an intelligence research center combines the features of a library, archives, laboratory and study. Its primary functions include collecting, processing, housing and servicing the accumulated information which forms the primary source material for finished intelligence. In addition, it must provide space for intelligence specialists to 
collate, digest and write up the results of their research. Its operations must be geared to provide maximum service and assistance to the intelligence staff, and all of its activities and efforts must be unified and directed toward that end.

$A$ sound and workable organization is basic to the unified and efficient operation necessary. Chart A presents in graphic form the bare outline of an intelligence agency. Chart $B$ shows schematically the outline of a research center and archives agency. The six divisions of the research center and archives might be constituted as follows:

Incoming Division: This unit handles incoming and outgoing mail; arranges for routing and proper distribution of material; assigns security classifications to material whenever needed.

Ordering Division: The order unit is responsible for selecting and acquiring through purchase, requisition, etc., the materials required for the center's activities,

Chart A

Intelligence Agency

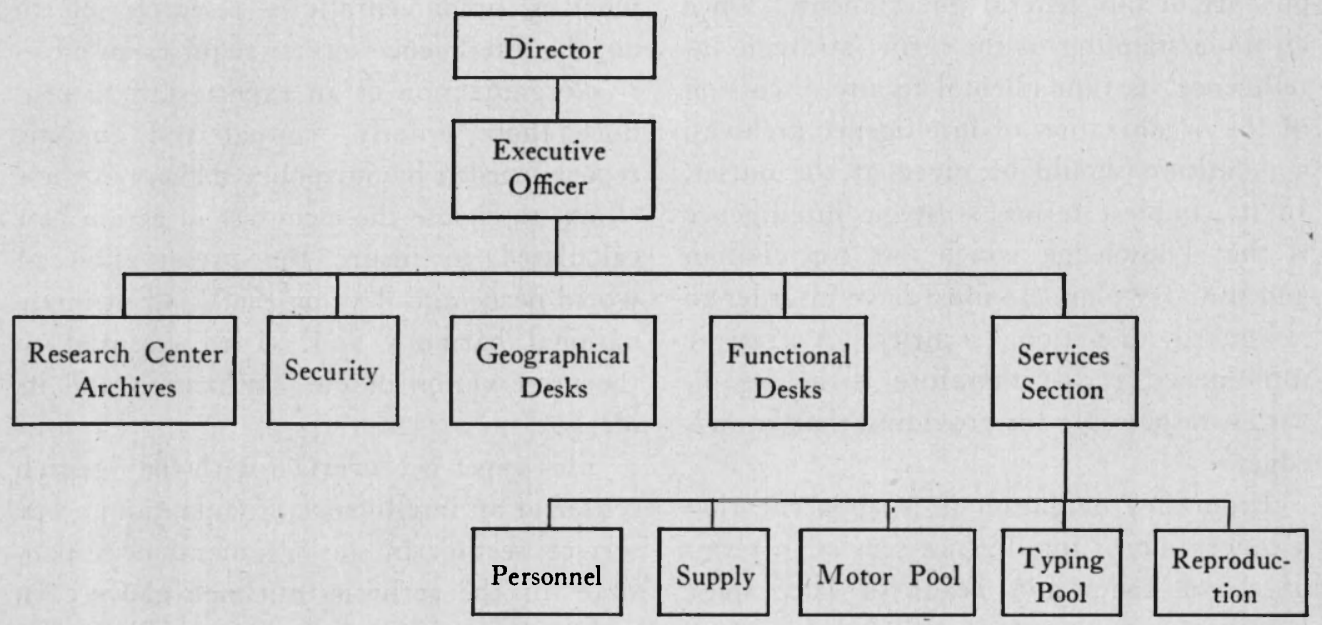

within the agency. Proper subdivision of duties within the research center are essential to its smooth operation and effectiveness. The suggested breakdown includes six divisions, each with its own division chief and all directly responsible to the director of the research center and his executive officer. The chief (director) in turn would rank equally with the department heads of the other units within the including intelligence reports, periodicals, newspapers, ephemeral materials, texts, etc. The division also maintains appropriate order and accession records and works in close cooperation with the agency's fiscal officer in allocating and controlling expenditures.

Technical Processes Division: Effective operation of the center depends in large measure upon the abilities of this group to 
classify, catalog, arrange and prepare materials for use. A suitable standardized cataloging code rigidly applied but flexible enough to take care of the wide variety of materials coming into the center is essential. An added problem of this division is the development of a suitable intelligence classification scheme which will bring both classified and unclassified materials into workable relationships.

Foreign Language Library: Since foreign languages introduce a difficult problem into intelligence service, special arrangements
Divisions, however.

Map Library: The need for and the use of maps and charts in an intelligence organization is very great. In addition to standard maps of the world's regions, the center must make available newly charted and special maps (e.g. physical or administrative maps) for which there is heavy demand. Proper maintenance of a constantly changing collection involves a special classification scheme, adequate and appropriately designed storage space, special problems of acquisition, and an orderly replacement schedule for used

Chart B

Research Center and Archives

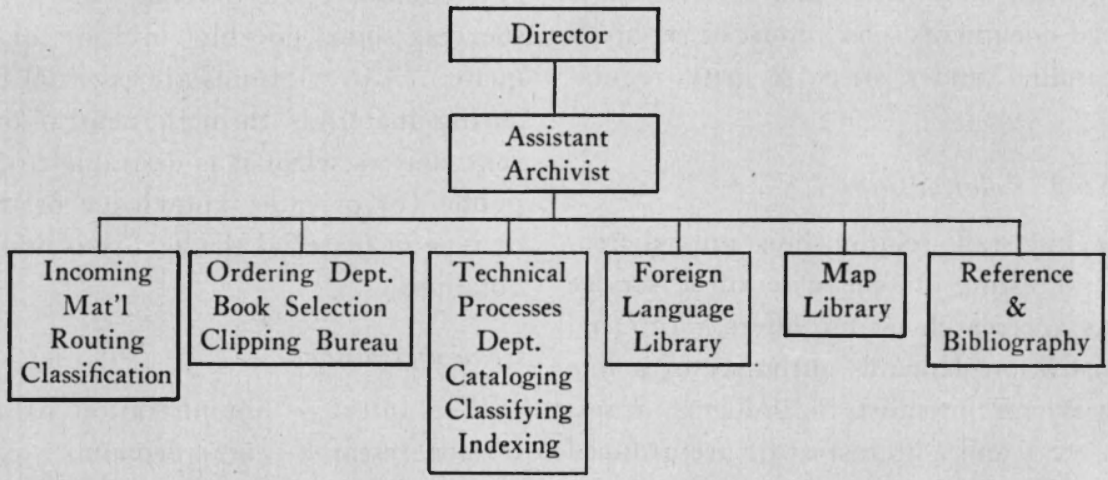

must be made to accommodate the language and area specialists who deal mainly in original research, translation and in the teaching of foreign languages. This problem can be most effectively solved through the establishment of a separate language library which will include both the personnel and collections necessary to spot promptly and evaluate the latest developments in foreign periodicals, news and reporting activities. Acquisition and processing activities for the language library will be centralized in the center's Order and Catalog maps. The special problems presented by a sizeable and heavily used map collection suggest the need for a separate division.

Reference and Bibliographic Service: The most evident result of efficient library service is the effectiveness of a research center's reference and bibliographic services. A great deal of emphasis should be placed on "getting answers." Otherwise, the mission of the center will not be fulfilled completely. Reference service demands top-notch performance, so adequate provision must be made for specialists who 
understand the mission of the organization and understand the technique of reference practice. Such service is provided most effectively by a separate reference division as the practice of most libraries indicates.

The administrative problems of an intelligence archives and research center fall into four groups, each of which is discussed below. These groups are (I) line-staff relationships; (2) fiscal considerations; (3) span of control; and (4) personnel.

In order to avoid confusion in the usage of terms, the following definitions are set forth:

Research Center: The department in which the various processes relative to bookcollecting, processing, servicing and research are carried on.

Archives: That part of the research center which administers and services those classified documents which must be set apart and handled under strict security regulations.

\section{Line-Staff Relationships}

The line-staff relationships are particularly interesting in the case of a service such as a research center offers. Internal administration demands authority of a line nature where specialists (catalogers, translators, etc.) and administrators are grouped together in one functional unit. Actually the director of each activity must wear two hats, in that he exercises the power of a line officer within his own organization at the same moment that he serves in an advisory staff capacity to his superiors in the hierarchy of command. For the most part, the director's subordinates are people who perform service functions almost entirely. Any problem of line administration is either settled by recourse to codified regulations or ultimate reference to the director's office.

\section{Fiscal Considerations}

Budgetary problems haunt any organiza- tion today. They are by no means unique. Both private and governmental agencies must give serious thought to the amount of money available and how it is to be apportioned. Discussion here will be confined not to the regular outline of fiscal structure, but rather to those problems of budget which stem from the nature of intelligence work. There are two major ones: sufficient freedom of use for the funds allocated to the research center, and the establishment of necessary clandestine "cover" funds. Freedom of fiscal disbursement and "cover" funds go hand in hand. If restrictions are placed on book funds, on the type of material to be purchased, or on maximum figures above which purchase is forbidden, the research mission of the agency is hampered in that research may be reduced to a reliance on secondary sources, some possibly inferior or inadequate. "Cover" funds are essential for procuring materials through neutral or innocent sources when it is desirable to prevent public (or private) knowledge of the kind or type of material the agency is desirous of obtaining.

\section{Span of Control}

The internal administration of a hightension research center demands a clear-cut span of control and a hierarchy of command. To burden the director with minor and mechanical problems involves him hopelessly in petty detail and interferes with his planning and directing of the whole activity. However, he must be sufficiently familiar with detail so that he may exercise his lineal authority intelligently and effectively. Experience has determined that a system of division chiefs best supervises the details of service and technique within their divisions. It is assumed that a suitable staff manual will have been prepared for their guidance. Information needed by the director or problems which he must settle 
are funneled from each division to his administrative assistant and finally, if necessary, to him. Thus a direct line of communications up and down the ladder is maintained and access to the director is provided for when necessary.

\section{Personnel}

No organization can function without good people. The problem of obtaining and training suitable personnel is, therefore, a vital one in the efficient operation of a research center. In an intelligence agency personnel is customarily handled for the entire agency, including the research center, by a services section. (See Chart A) Close liaison between the personnel officer and the director of the research center is, therefore, of major importance. Ideally, the director will establish the standards for hiring librarians, specialists and other needed help.

The director of an intelligence research center should be a combination of professional librarian, experienced intelligence specialist and trained administrator. Without these qualifications he will be handicapped in understanding the mission of his organization and relating its operations and techniques to those of the intelligence agency. Ideally, the division chiefs should have similar qualifications, but such combinations of experience are rare indeed. Therefore, carefully devised job descriptions, which describe duties and responsibilities accurately and emphasize the function to be performed, are necessary in establishing and filling positions. For example, it will be more desirable for the center to employ an experienced cataloger with no or limited experience in intelligence work than an intelligence officer with knowledge of cataloging. Considered opinion stemming from the lessons of nine years of strategic intelligence operations points out that in matters of personnel a compromise must be accepted. Ideallytrained people are difficult or even impossible to find; instead, area specialists, librarians, intelligence officers, etc. must be employed and molded and trained into an ordered, workable staff. When such distinct professional groups are banded together to accomplish a specific goal, personal and professional rivalries must be subordinated to the common effort if the center is to operate smoothly and efficiently. This requires skilled personnel administration by the director, for legislation or rule-making can aid in eliminating the rivalries and the problems. In the final analysis, the personality and professional ability of the director will determine how successful this mixed marriage will be.

Some of the more pressing problems of an intelligence archives deserve particular attention. Although no dogmatic solution can be offered, some of the ways in which these problems have been solved will be indicated.

\section{Security}

Perhaps the most constant and ever restricting problem confronted in a research center is that of security. The nature of any intelligence operation demands that the secrecy of many projects and activities be insured. But, security, which involves loyalty checks of staff members and constant vigilance over the custody, use and location of classified material, works restrictively against the free flow of information and data in and out of the research center. There is no alternative; responsibility placed must be accepted and upheld. However, classified materials are loaned to people who have been cleared for intelligence work (and it is assumed analysts and researchers, and even the janitors, are "good security risks") on the basis of signed custody receipts which transfer the responsibility for protection from the research center 
to the interested staff member. This method is essentially the same as a public library charging system.

\section{Maps}

Maps are an increasing source of difficulty. For some unknown reason, intelligence workers treat maps carelessly. To be sure, they use quantities of them at all times, but they do not treat a chart or a map with the same care as a book or a periodical. When research men have completed a project or finished with the maps, they usually mutilate them, destroy them, forget them, or simply ignore them. $\mathrm{Na}$ turally this cavalier treatment of maps brings the analysts into open conflict with the library, and the library with various governmental mapping agencies, all of which are interested in eliminating waste. Unquestionably a certain amount of overlay work and grease-pencil work is necessary on maps used for research. But with the map supply short and the demand high, it is necessary to prescribe rigid rules governing expendable use of maps, to establish good liaison relationships which make possible the procurement of both old and new well in advance of deadline dates, and to build reference collection of maps-complete, current, carefully selected to meet the average needs of the staff. Maps in this collection are classified and cataloged and loaned like material in the center subject, of course, to security classification and the needs of other workers.

\section{Publicity}

The intelligence archives handles thousands of documents each week. They must be accessioned, routed, called to the attention of interested parties and filed for future use. Naturally, routing must be done selectively for it is impossible to distribute several hundred documents per day. To offset some of this selection, the center endeavors to publicize more of its acquisitions. This publicity may be of several kinds: indexes, abstracts, annotated bibliographies, departmental records or reading "logs." In these ways the center makes available a summary of the most important and valuable archival acquisitions during a given period. Such publicized notices presuppose an intimate knowledge of the major projects and long-term goals of the research and language staffs. Through these devices highlighted materials are made known to the people who must know about them or use them.

\section{Subject Analysis}

One of the inherent difficulties in operating an intelligence organization results from the division of work between units organized along geographical lines and those organized on functional lines. Briefly, an organization of intelligence activities is confounded by the lack of agreement on whether world coverage of information should be divided by geographical area or by subject, e.g. should sociologists, economists, etc. be responsible for intelligence on all of the world's sociological problems without regard for geographic boundaries, or should units responsible for intelligence on given world areas maintain a sociological or economic section. Both systems have been tried, separately and simultaneously, and no attempted recommendations will be suggested here. But as opinions and systems change, the research center must continue to function. These two organizational patterns affect directly the policy which the center must adopt in its subject analysis of materials. Shall a subject be divided geographically or a country by subject? Since no final answer can be given, subject headings must be chosen which will be flexible enough to handle intelligence 
either geographically or by subject. A parallel problem exists in classification, particularly for the archival (i.e. secret) material. Ordinarily, the regular book collection can be organized according to some existing classification scheme. However, restricted material intended solely for intelligence use cannot be processed according to regular methods. A system which will provide adequate cross indexing and referencing but which is flexible enough to stand up under great expansion is necessary. There is ample room here for the application of new ideas and techniques. Ultimately such ideas may aid in the development of general library service since they question and re-evaluate traditional library habits and techniques.

\section{Reproduction}

Reproduction and graphics, two considerations which deserve mention, are outside the scope of research center administration in a typical intelligence agency organization. Since much of the center's work is distributed and posted, agreements must be made to insure the prompt completion of displays, publicity and printing assignments. This is a matter of some administrative concern when reproduction facilities are not available. Hence, careful planning and advance preparation can prevent needless worry and delay.

\section{Language Library}

In order to satisfy the needs of language specialists most effectively, a separate departmental library seems to be the best solution, even though it adds administrative problems. Such a library reduces the work load on the general center and archives and places the language specialist in more immediate contact with the materials with which he works. Such special libraries come under the administration of the research center and the library's ordering and cataloging activities are centralized in the technical processes division. This departmental arrangement is a convenient service arrangement only.

\section{Liaison}

Because a strategic intelligence acquisition program is world wide in scope, it is necessary to have overseas contacts. Such agents must not only be trustworthy, they must also be in positions to know what information to pick up and what to reject. A simple system of fiscal accounting to handle overseas acquisitions and easy communications is desirable. Effective use of American overseas representatives offers the best method of obtaining material to date. It is equally important that there be complete understanding of the research center's relations to the intelligence agency and to other government offices so that all contacts for obtaining materials and data may be exploited. Without cooperation no amount of organization can make the movement successful.

\section{Training}

The research center is, of course, directly concerned with on-the-job training for both professional and subprofessional personnel. Such training is absolutely essential when people of such varying interests, education and experience are employed in a common enterprise. No specific program is outlined here, but the need for effective on-the-job training programs cannot be too strongly emphasized.

\section{Space}

Some note should be made here of the need for adequate working and storage space. Two points must be kept in mind. Space in which classified material is stored (Continued on page 232) 
special displays of books in the browsing area and on the first floor.

By the time we can build the other wing, library fashions may have changed completely, but nonetheless we have definite ideas as to what should go into it. The original plans called only for a reading room-no basement, no second floor. But now we plan to ask for basement, first floor, second floor and attic, just as we have in the present wing. We believe that we shall require all this space for special reading rooms, map room, rooms for reading machines, individual seminar or conference rooms, a small auditorium for motion picture projection and a room for archives storage. In addition to this wing, provision is made for extension toward the south, and if necessary in the distant future, the building could be completed in a hollow square. The simplicity of the present structure makes it very flexible.

\section{The Administration of Intelligence Archives}

\section{(Continued from page 219)}

constitutes a special problem, for government regulations are demanding. Secondly, an intelligence research center grows rapidly despite careful weeding. Therefore, due consideration for security and growth should govern the allocation of space for the center when it is set up. Poor working conditions, frayed nerves and crowded quarters are not conducive to effective research which requires as much quiet and academic environment as a government building will allow.

In summary then, it may be said that the concept of a research center and intelligence archives is a relatively new extension of library service. It is a testing ground for new techniques of library administration, new machines and new approaches to cataloging and classification. Inventiveness, clear thinking and the ability to work under pressure are particular qualifications needed by people engaged in such professional work. Since no final solution has been found for the multitude of problems presented, an open mind is essential. Most important, an efficient research center demands good organization; a strong administrator in whom is combined a knowledge of librarianship and an appreciation of intelligence service; and a staff alert to new ideas and ready to capitalize on them in improving service, making materials available promptly and facilitating the work of other intelligence workers, thus furthering the mission of U.S. strategic intelligence. 